\title{
Fate in Soil of Flavonoids Released from White Clover (Trifolium repens L.)
}

\author{
Sandra C. K. Carlsen, Hans A. Pedersen, Niels H. Spliid, and Inge S. Fomsgaard \\ Department of Agroecology, Aarhus University, Forsøgsvej 1, Flakkebjerg, 4200 Slagelse, Denmark \\ Correspondence should be addressed to Inge S. Fomsgaard, inge.fomsgaard@agrsci.dk
}

Received 15 June 2011; Accepted 23 September 2011

Academic Editor: D. L. Jones

Copyright ( $) 2012$ Sandra C. K. Carlsen et al. This is an open access article distributed under the Creative Commons Attribution License, which permits unrestricted use, distribution, and reproduction in any medium, provided the original work is properly cited.

White clover is frequently used as a leguminous cover crop, serving as green manure, and is also included with grasses in cattle feed mixtures. Numerous biological effects reported for clover cultivation have been attributed to the production of bioactive secondary metabolites. Thus far the presence in soil of bioactive secondary metabolites from clover has received limited attention. In this paper we examine for the first time the release of flavonoids both from field-grown white clover and from soil-incorporated white clover plants of flavonoids, as analyzed by LC-MS/MS. The dominant flavonoid aglycones were formononetin, medicarpin, and kaempferol. Soil-incorporated white clover plants generated high concentrations of the glycosides kaempferol-Rha-Xyl-Gal and quercetin-Xyl-Gal. Substantial amounts of kaempferol persisted in the soil for days while the other compounds were degraded faster. These compounds should be considered in future studies of soil fatigue, allelopathic activity, and possible environmental risks from extended clover cultivation.

\section{Introduction}

Sustainable agricultural practices include the use of leguminous plants to supply the soil with nitrogen in a crop rotation strategy to limit the use of agrochemicals. The leguminous crop white clover is frequently used as a cover crop serving as green manure and is also included in mixtures with grasses for cattle feed. Legumes that are used as cover crops or incorporated into the soil may also function as a supplement or even replacement for pesticides. Several studies have reported suppressive effects of white clover on weed pressure and diseases or unexplained failure of oversown grasses in swards dominated by clover [1-12]. Secondary metabolites have been suspected of causing these effects, and basic knowledge on the release, active or passive, of biologically active secondary metabolites from white clover is therefore much needed. Such knowledge would aid an evaluation of the importance of secondary metabolites in biological effects from white clover. The objective of this study was therefore to clarify the pattern of both flavonoid release from field-grown white clover and their leaching into soils amended with white clover plant material.

\section{Materials and Methods}

2.1. Origin of White Clover and Sampling. Whole plants of the white clover cultivar Klondike were collected in June 2008 along with soil to a depth of $15 \mathrm{~cm}$ from an organically grown field in Flakkebjerg, Denmark (soil A). The soil was carefully removed from the plant material. To determine the flavonoid concentration and the relative distribution within the different plant parts, plant material from a $17 \times 17 \mathrm{~cm}$ plot was divided into roots, stems, leaves, and flowers. The material was weighed, lyophilized, weighed again, ground to a powder, and stored at $-18^{\circ} \mathrm{C}$ until analysis (see Table 1 ).

2.2. Soil Data. Soil A was collected from the field used for cultivating the clover plants as described in Section 2.1. Prior to analysis, it was sieved, lyophilized, and stored at $-18^{\circ} \mathrm{C}$. Before cultivation of the white clover cultivar Klondike in 2008 for the present study, the field had previously been used in 2003 for cultivation of the white clover cultivar Sonja for use as green manure, in 2004 for a mixture of spring barley and oat, in 2005 for a mixture of spring barley and peas for fodder production, in 2006 for spring barley undersown with 
TABLE 1: Distribution of morphological components of white clover from a $17 \times 17 \mathrm{~cm}$ field plot.

\begin{tabular}{|c|c|c|c|c|c|}
\hline \multirow[t]{2}{*}{ Plant part } & \multicolumn{2}{|c|}{ Wet plant material } & \multicolumn{2}{|c|}{ Dry plant material } & \multirow{2}{*}{$\begin{array}{c}\text { Water content } \\
(\% \text { of wet material })\end{array}$} \\
\hline & Weight (g) & $\%$ of total & Weight (g) & $\%$ of total & \\
\hline Roots & 4.5 & $3.7 \%$ & 2.5 & $6.8 \%$ & $44.6 \%$ \\
\hline Stems & 87.0 & $72.8 \%$ & 24.8 & $67.8 \%$ & $71.5 \%$ \\
\hline Leaves & 19.0 & $15.9 \%$ & 6.2 & $16.8 \%$ & $67.6 \%$ \\
\hline Flowers & 9.1 & $7.6 \%$ & 3.1 & $8.6 \%$ & $65.5 \%$ \\
\hline Total & 120 & - & 36.6 & - & $69.4 \%$ \\
\hline
\end{tabular}

the white clover cultivar Milo, and in 2007 for the white clover cultivar Milo. The characteristics of soil A were as follows (parentheses indicate particle sizes): clay $(<2 \mu \mathrm{m})$, $16.8 \%$; silt $(2-20 \mu \mathrm{m}), 13.2 \%$; coarse silt $(20-63 \mu \mathrm{m}), 12.8 \%$; fine sand $(63-200 \mu \mathrm{m}), 34.5 \%$; coarse sand $(200-2000 \mu \mathrm{m})$, 20.7\%; organic carbon, $1.1 \%$; potassium, $8 \mathrm{mg} / 100 \mathrm{~g}$ soil; total phosphorus, $1.9 \mathrm{mg} / 100 \mathrm{~g}$ soil; magnesium, $3.9 \mathrm{~g} / 100 \mathrm{~g}$ soil; $\mathrm{pH}\left(\mathrm{H}_{2} \mathrm{O}\right), 6.5$; and water content, $4.8 \%$. Soil $\mathrm{B}$, a sandy loam soil used for the incorporation experiments (see Section 2.3.) to study leaching and transformation, was sampled in spring 2007 from the upper $30 \mathrm{~cm}$ of a conventionally cultivated field in Flakkebjerg, Denmark. It had previously been used in 2003 for cultivation of winter wheat, in 2004 for oat, in 2005 for winter barley, and in 2006 for spring rape. The characteristics of soil B were as follows (parentheses indicate particle sizes): clay $(<2 \mu \mathrm{m})$, 17.1\%; silt (2-20 $\mu \mathrm{m}), 21.9 \%$; coarse silt (20-63 $\mu \mathrm{m}), 14.3 \%$; fine sand (63-200 $\mu \mathrm{m}), 25.6 \%$; coarse sand $(200-2000 \mu \mathrm{m})$, $18.8 \%$; organic carbon, $1.3 \%$; potassium, $10.4 \mathrm{mg} / 100 \mathrm{~g}$ soil; total phosphorus, $3.8 \mathrm{mg} / 100 \mathrm{~g}$ soil; magnesium, $6.5 \mathrm{~g} / 100 \mathrm{~g}$ soil; $\mathrm{pH}\left(\mathrm{H}_{2} \mathrm{O}\right)$, 5.7; water content, $4.3 \%$; and water holding capacity (WHC), 44\% (field capacity, 22\%). The soil was sieved prior to use in the incorporation experiment. Additionally, a portion of the soil was lyophilized and used as a blank sample as well as for the determination of recovery, matrix effect, and detection limits.

2.3. Incorporation Experiment. Whole plants were collected from a $56.5 \mathrm{~cm} \times 36.5 \mathrm{~cm} \times 20 \mathrm{~cm}$ plot, weighed (wet weight: $939.0 \mathrm{~g}$ ) and cut into pieces of $1 \mathrm{~cm}$. The plant material was then deposited on top of $34 \mathrm{~kg}$ of soil B in a plastic container of the same area as the original plot but slightly shallower $(56.5 \mathrm{~cm} \times 36.5 \mathrm{~cm} \times 18 \mathrm{~cm})$. The dry weight percentage of plant material added was $0.87 \%$. The soil-plant mixture was then placed outdoors and watered to half of the WHC. During the incubation, the container with the soilplant mixture was weighed regularly and water content was adjusted to half of the WHC. A tube (diameter: $6 \mathrm{~cm}$, height: $4.3 \mathrm{~cm}$ ) was used for sampling approximately $190 \mathrm{~g}$ of soil at each sampling time. Samples were taken at days $0,1,2,3,5$, 6,8 , and 16 , starting from the day of incorporation of the white clover plant material into the soil. After sampling, the soil was frozen at $-18^{\circ} \mathrm{C}$ and lyophilized. All plant material was manually removed from the soil sample. The soil samples were subsequently sieved and the plant samples were ground. The mean dry weight of each soil sample was $156 \pm 4 \mathrm{~g}$ and the mean dry weight of the plant material was $1.3 \pm 0.7 \mathrm{~g}$. The dry weight of the plant material removed from soil samples was $0.83 \pm 0.11 \%$, indicating that nearly all plant material had been successfully separated.

2.4. Solutions and Chemicals. Kaempferol (96\%), formononetin (99\%), and coumestrol (95\%) were purchased from Fluka (Brøndby, Denmark). Quercetin dihydrate (98\%), biochanin A (97\%), and astragalin (99\%), were purchased from Sigma-Aldrich (Brøndby, Denmark). Kaempferol-RhaGlc (99\%) and hyperoside (99\%) were purchased from Roth (Karlsruhe, Germany). Daidzein (97\%) and genistein (97\%) were purchased from Lancaster (Brønshøj, Denmark). Quercitrin (98.5\%), rutin (99\%), apigenin (99\%), isovitexin (99\%), saponarin (99\%), luteolin (99\%), luteolin-Glc (95\%), luteolin-di-Glc (95\%), naringenin (99\%), daidzin (90\%), and puerarin (99\%) were purchased from Extrasynthèse (Genay, France). See Table 2 for systematic names and CAS numbers. Kaempferol-Rha-Xyl-Gal, quercetin-Xyl-Gal, and quercetin-Rha-Xyl-Gal (Table 2) were isolated from white clover, purified, and identified by their UV, mass, and NMR spectra as part of a previous study [13]. Medicarpin was obtained from Dr. Paul M. Dewick at the University of Nottingham, England. Stock flavonoid solutions of $1 \mathrm{~g} / \mathrm{L}$ were prepared by dissolution in methanol and dimethylsulfoxide. Working standard solutions of the 30 compounds were obtained by serial dilution of the stock standard solutions in 35\% acetonitrile and 65\% MilliQ water (v/v) containing $20 \mathrm{mM}$ acetic acid. Three mixed standard curves for the aglycones and two for the glycosides were generated from eight concentrations of each standard and used for quantification.

2.5. Plant and Soil Extraction and Quantification of Flavonoids by LC-MS/MS. Each lyophilized soil or plant sample was placed in a $50 \mathrm{~mL}$ Falcon tube and suspended in $5 \mathrm{~mL} 70 \%$ methanol. For soil samples $5 \mathrm{~g}$ were used and for plant samples $0.3 \mathrm{~g}$ were used. The samples were sonicated for $10 \mathrm{~min}$ and extracted for $4 \mathrm{~h}$ at room temperature on an Elmi (Riga, Latvia) Intelli-Mixer at $21 \mathrm{rpm}$. After extraction, the test tubes were centrifuged at $4200 \mathrm{rpm}$ for $10 \mathrm{~min}$ on a Heraeus (Albertslund, Denmark) Multifuge 3 S-R. The supernatant was removed, diluted 1:1 with MilliQ water, filtered through a Sartorius (Taastrup, Denmark) SRP 15 $0.45 \mu \mathrm{m}$ PTFE membrane filter, and quantified on an AB Sciex (Nærum, Denmark) API 2000 instrument. A Thermo 
TABLE 2: Common and systematic names and CAS numbers of compounds quantified in white clover in the present study.

\begin{tabular}{|c|c|c|c|c|}
\hline Chemical group & Common name & Systematic name & $\mathrm{M}(\mathrm{g} / \mathrm{mol})$ & CAS no. \\
\hline \multirow{10}{*}{ Flavonols } & Kaempferol & $3,4^{\prime}, 5,7$-Tetrahydroxyflavone & 286.24 & $520-18-3$ \\
\hline & Astragalin & Kaempferol-3-O-glucoside & 448.39 & $480-10-4$ \\
\hline & Kaempferol-Rha-Glc & 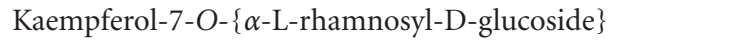 & 594.53 & $13353-03-6$ \\
\hline & Kaempferol-Rha-Xyl-Gal & $\begin{array}{l}\text { Kaempferol-3-O- }\{\beta \text {-D-rhamnosyl- }(1 \rightarrow 6)-[\beta \text {-D-xylosyl- } \\
(1 \rightarrow 2)]-\beta \text {-D-galactoside }\}\end{array}$ & 726.63 & - \\
\hline & Quercetin & $3,3^{\prime}, 4^{\prime}, 5,7$-Pentahydroxyflavone & 302.24 & $117-39-5$ \\
\hline & Quercitrin & Quercetin-3-O- $\alpha$-L-rhamnoside & 448.38 & $522-12-3$ \\
\hline & Hyperoside & Quercetin-3-O- $\beta$-D-galactoside & 464.38 & $482-36-0$ \\
\hline & Quercetin-Xyl-Gal & 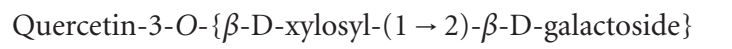 & 596.49 & - \\
\hline & Rutin & Quercetin-3-O-rutinoside & 610.52 & $153-18-4$ \\
\hline & Quercetin-Rha-Xyl-Gal & 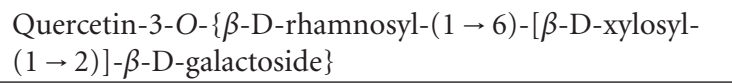 & 742.63 & - \\
\hline \multirow{6}{*}{ Flavones } & Apigenin & $4^{\prime}, 5,7$-Trihydroxyflavone & 270.24 & $520-36-5$ \\
\hline & Isovitexin & Apigenin-6-C-glucoside & 432.38 & $38953-85-4$ \\
\hline & Saponarin & Isovitexin-7-O-glucoside & 594.52 & $20310-89-8$ \\
\hline & Luteolin & $3^{\prime}, 4^{\prime}, 5,7$-Tetrahydroxyflavone & 286.24 & 491-70-3 \\
\hline & Luteolin-Glc & Luteolin-4'-O-glucoside & 448.38 & $6920-38-3$ \\
\hline & Luteolin-di-Glc & Luteolin-3',7-di-O-glucoside & 610.53 & $52187-80-1$ \\
\hline Flavanone & Naringenin & $4^{\prime}, 5,7$-Trihydroxyflavanone & 272.26 & 480-41-1 \\
\hline \multirow{8}{*}{ Isoflavones } & Daidzein & $4^{\prime}, 7$-Dihydroxyisoflavone & 254.24 & $486-66-8$ \\
\hline & Daidzin & Daidzein-7-O-glucoside & 416.38 & $552-66-9$ \\
\hline & Puerarin & Daidzein-8-C-glucoside & 416.38 & $3681-99-0$ \\
\hline & Formononetin & 7-Hydroxy-4'-methoxyisoflavone & 268.27 & $485-72-3$ \\
\hline & Genistein & $4^{\prime}, 5,7$-Trihydroxyisoflavone & 270.24 & $446-72-0$ \\
\hline & Genistin & Genistein-7-O- $\beta$-D-glucoside & 432.38 & $529-59-9$ \\
\hline & Biochanin A & 5,7-Dihydroxy-4' -methoxyisoflavone & 284.27 & $491-80-5$ \\
\hline & Sissotrin & Biochanin A-7-O-glucoside & 446.40 & $5928-26-7$ \\
\hline Pterocarpan & Medicarpin & Demethylhomopterocarpin & 270.28 & $33983-40-3$ \\
\hline Coumestan & Coumestrol & 7,12-Dihydroxycoumestan & 268.23 & 479-13-0 \\
\hline
\end{tabular}

(Copenhagen, Denmark) BDS hypersil C18 column $(250 \times$ $2.1 \mathrm{~mm}$ id, $5 \mu \mathrm{m}$ particle size) was used for the aglycones, while a Phenomenex (Allerød, Denmark) Synergi Polar-RP $80 \mathrm{~A}$ column $(250 \times 2 \mathrm{~mm}$ id, $4 \mu \mathrm{m}$ particle size $)$ was used for the glycosides. Aglycones were separated using a binary gradient according to the following method: $0-3 \mathrm{~min}, 100 \%$ $\mathrm{A}$, isocratic; $3-13 \mathrm{~min}, 100-20 \% \mathrm{~A}$, gradient; $13-16 \mathrm{~min}$, $20 \% \mathrm{~A}$, isocratic; $16-20 \mathrm{~min}, 20-0 \% \mathrm{~A}$, gradient; $20-23 \mathrm{~min}$ $0 \% \mathrm{~A}$, isocratic; $23-24 \mathrm{~min}, 0-100 \% \mathrm{~A}$, gradient; and 2429 min, $100 \%$ A, isocratic. Glycosides were separated using a binary gradient according to the following method: $0-5 \mathrm{~min}$, $81 \% \mathrm{~A}$, isocratic; 5-15 min, $81-78 \% \mathrm{~A}$, gradient; $15-28 \mathrm{~min}$, 78-40\% A, gradient; $28-30 \mathrm{~min}, 40-0 \%$ A, gradient; 30 $35 \mathrm{~min}, 0 \% \mathrm{~A}$, isocratic; $35-36 \mathrm{~min}, 0-81 \% \mathrm{~A}$, gradient; and $36-46 \mathrm{~min}, 81 \% \mathrm{~A}$, isocratic. The flow rate was $200 \mu \mathrm{L} \mathrm{\textrm {min } ^ { - 1 }}$ in both methods. Solvent A was composed of 7\% aqueous acetonitrile and solvent B contained 78\% acetonitrile. Both solvents contained $20 \mathrm{mM}$ acetic acid. Mass spectrometric detection was performed in multiple reaction mode (MRM) using atmospheric pressure electrospray ionization in positive mode for the glycosides and negative mode for the aglycones. Retention times and MRM transitions (Q1/Q3) are listed in Table 3. Chromatographic peaks were assigned by comparison of retention times and MRM transitions with reference compounds.

2.6. Validation of the Analytical Method. The limit of detection $\left(L_{D}\right)$ and recovery of flavonoids from soil were estimated by spiking samples of soil B with aglycones to a concentration of $250 \mathrm{ng} / \mathrm{g}$ (dry weight) and with glycosides to a concentration of $150 \mathrm{ng} / \mathrm{g}$ (dry weight), as shown in Table 4 . The $L_{D}$ and recovery for both glycosides and aglycones in plant samples were estimated by spiking samples of Amaranthus hypochondriacus cv. Criolla to a concentration of $667 \mathrm{ng} / \mathrm{g}$ (dry weight). A. hypochondriacus was used because it was devoid of 23 of the 27 compounds investigated. Spiked samples were extracted as previously described, but with six replicates. The standard deviation, $S$, of the measured concentrations was calculated for each compound, and the $L_{D}$ taken as $3 S$. Recovery and detection limits in plants could not be determined for rutin, astragalin, quercetin, and hyperoside as these compounds were abundant in the blank 
TABLE 3: Mass-to-charge ratio $(\mathrm{m} / \mathrm{z})$ used in selected ion monitoring and retention times.

\begin{tabular}{lccl}
\hline Compound & $t_{R}(\mathrm{~min})$ & $\mathrm{Q} 1(\mathrm{~m} / z)$ & $\mathrm{Q} 3(\mathrm{~m} / z)$ \\
\hline & Aglycones & & \\
\hline Daidzein & 19.0 & 253 & 223 \\
Luteolin & 19.2 & 285 & 133 \\
Quercetin & 19.4 & 301 & 151 \\
Apigenin & 20.2 & 269 & 117 \\
Coumestrol & 20.2 & 266 & 166 \\
Naringenin & 20.4 & 271 & 151 \\
Genistein & 20.4 & 269 & 133 \\
Kaempferol & 20.4 & 285 & 239 \\
Formononetin & 21.2 & 267 & 252 \\
Medicarpin & 22.4 & 269 & 254 \\
Biochanin A & 23.0 & 283 & 268 \\
\hline & Glycosides & & \\
\hline Puerarin & 5.83 & 417 & 297 \\
Saponarin & 7.59 & 595 & 433 \\
Quercetin-Rha-Xyl-Gal & 6.96 & 743 & 303 \\
Luteolin-di-Glc & 9.62 & 611 & 287 \\
Daidzin & 9.39 & 417 & 255 \\
Quercetin-Xyl-Gal & 9.67 & 597 & 303 \\
Kaempferol-Rha-Xyl-Gal & 9.64 & 727 & 287 \\
Rutin & 10.6 & 611 & 303 \\
Isovitexin & 12.4 & 433 & 313 \\
Hyperoside & 14.4 & 465 & 303 \\
Genistin & 18.8 & 433 & 271 \\
Astragalin & 20.3 & 449 & 287 \\
Kaempferol-Rha-Glc & 20.8 & 595.5 & 287 \\
Quercitrin & 21.3 & 449 & 303 \\
Luteolin-Glc & 23.8 & 449 & 287 \\
Sissotrin & 31.2 & 447 & 285 \\
\hline
\end{tabular}

sample. The analytical method was less sensitive toward kaempferol and was hampered by the instability of quercetin in solution. All other compounds were stable when kept for 74 hours at room temperature. Sample flavonoid contents were not adjusted for their recovery percentages [14]. Concentrations measured in soil were taken as the available amounts not lost to soil sorption. Finally the organic carbonnormalized sorption coefficients $\left(K_{\mathrm{OC}}\right)$ for four flavonoid aglycones were estimated using the program PCKOCWIN from the United States Environmental Protection Agency.

\section{Results}

3.1. Recovery of Flavonoids during Extraction. Recovery values in spiked plant samples (Table 4) were between 69 and $149 \%$ for all compounds except quercetin-Rha-Xyl-Gal $(173 \%)$ and luteolin (204\%). Flavonoid recovery values for spiked soil samples were low by comparison, suggesting significant soil sorption.
3.2. Flavonoid Concentrations in White Clover. The distributions of flavonoids in plants are listed in Table 5. In decreasing order of molar quantities per dry weight, the most prominent flavonoids found were formononetin $\gg$ medicarpin $\gg$ saponarin in roots, formononetin $\gg$ medicarpin $>$ quercetin-Xyl-Gal > kaempferol-Rha-Xyl-Gal in stalk and stems, quercetin-Xyl-Gal > formononetin > kaempferolRha-Xyl-Gal > medicarpin > hyperoside in leaflets, hyperoside $>$ formononetin $\approx$ quercetin-Xyl-Gal $>$ medicarpin $>$ kaempferol-Rha-Xyl-Gal > Quercetin-Rha-Xyl-Gal in flowers, and formononetin > quercetin-Xyl-Gal > medicarpin $>$ kaempferol-Rha-Xyl-Gal > hyperoside in whole plants. The glycosides puerarin, isovitexin, quercitrin, and kaempferolRha-Glc were detected neither in white clover plants nor in soil. Flavonoids were mainly present as glycosides in the plant samples, but the type of glycosylation differed depending on location within the plant (Table 5).

Medicarpin and formononetin aglycones represented the majority of isoflavonoids in all parts of the plants. The concentration of aglyconic formononetin, the most abundant white clover isoflavone, varied between $0.7 \mathrm{mg} / \mathrm{g}$ in roots and $1.3 \mathrm{mg} / \mathrm{g}$ in stalks and stems (dry weight). Much higher concentrations of quercetin and kaempferol aglycones were observed in white clover flower heads than in leaflets, stalks, stems, or roots. The leaflets contained a significantly higher concentration of quercetin-Xyl-Gal than other parts of the plant.

3.3. Fate in Soil of Flavonoids Released from Living White Clover Plants. Clover cultivation gave rise to high concentrations (all given as dry weight) of the biologically active aglycones formononetin $(9114 \mathrm{nmol} / \mathrm{kg})$, medicarpin $(832 \mathrm{nmol} / \mathrm{kg})$ and kaempferol $(520 \mathrm{nmol} / \mathrm{kg})$ as detected, in soil A. These concentrations were found in mixed soil samples from field samples where white clover was grown.

3.4. Fate of Flavonoids in Soil Amended with White Clover. Concentrations of glycosides and aglycones resulting from leaching of flavonoids into soil amended with plant material reached their highest levels at $0-1$ and 2-5 days, respectively (Figure 1). The most abundant aglycones leached from soilincorporated clover were the same as those most released during clover cultivation ( $t$ indicates the time of concentration maxima): formononetin ( $10.2 \mathrm{mmol} / \mathrm{kg}, t=2$ days $)$, medicarpin $(3.9 \mathrm{mmol} / \mathrm{kg}, t=2$ days $)$, and kaempferol $(1.4 \mathrm{mmol} / \mathrm{kg}, t=5$ days $)$. Additional glycosides were also detected: kaempferol-Rha-Xyl-Gal (3.4 mmol/ $\mathrm{kg}, t=5$ days $)$ and quercetin-Xyl-Gal $(0.5 \mathrm{mmol} / \mathrm{kg}, t=0$ days $)$. The rest of the analyzed compounds were either only present in minor amounts or not detected at all (Figure 1). All concentrations are given as dry weight.

\section{Discussion}

4.1. Distribution of Flavonoids in Plants. We have previously suggested that not only flavonoids are glycosylated for storage but also the glycosides have additional biological functions within the plant [13]. It follows that measuring 
TABLE 4: Recovery (\%) and detection limits (molar quantities per dry weight) of quantified compounds in plants and soil, respectively.

\begin{tabular}{|c|c|c|c|c|}
\hline \multirow[t]{2}{*}{ Compound } & \multicolumn{2}{|c|}{ Soil } & \multicolumn{2}{|c|}{ Plant } \\
\hline & Recovery $^{\mathrm{a}}$ & $\begin{array}{c}\text { LOD } \\
(\mathrm{nmol} / \mathrm{kg})\end{array}$ & Recovery ${ }^{\mathrm{a}}$ & $\begin{array}{c}\text { LOD } \\
(\mu \mathrm{mol} / \mathrm{kg})\end{array}$ \\
\hline Kaempferol & $\mathrm{ND}$ & $>873$ & $142 \% \pm 10$ & 5 \\
\hline Astragalin & $27 \% \pm 1$ & 17 & - & - \\
\hline Kaempferol-Rha-Glc & $6 \% \pm 0$ & 5 & $121 \% \pm 1$ & 0.3 \\
\hline Kaempferol-Rha-Xyl-Gal & $52 \% \pm 1$ & 30 & $135 \% \pm 2$ & 0.2 \\
\hline Quercetin & ND & $>827$ & - & - \\
\hline Quercitrin & $10 \% \pm 1$ & 8 & $149 \% \pm 2$ & 0.4 \\
\hline Hyperoside & $9 \% \pm 1$ & 12 & - & - \\
\hline Quercetin-Xyl-Gal & $13 \% \pm 1$ & 20 & $139 \% \pm 5$ & 6 \\
\hline Rutin & $7 \% \pm 1$ & 31 & - & - \\
\hline Quercetin-Rha-Xyl-Gal & $14 \% \pm 1$ & 8 & $173 \% \pm 2$ & 0.4 \\
\hline Apigenin & $8 \% \pm 1$ & 37 & $87 \% \pm 3$ & 0.5 \\
\hline Isovitexin & $23 \% \pm 1$ & 20 & $103 \% \pm 3$ & 0.6 \\
\hline Saponarin & $24 \% \pm 1$ & 28 & ND & $>1.12$ \\
\hline Luteolin & $7 \% \pm 4$ & 177 & $204 \% \pm 6$ & 2 \\
\hline Luteolin-Glc & $11 \% \pm 1$ & 14 & $98 \% \pm 2$ & 0.9 \\
\hline Luteolin-di-Glc & $16 \% \pm 1$ & 14 & $91 \% \pm 2$ & 0.2 \\
\hline Naringenin & $44 \% \pm 1$ & 52 & $90 \% \pm 2$ & 0.4 \\
\hline Daidzein & $43 \% \pm 1$ & 61 & $83 \% \pm 3$ & 0.4 \\
\hline Daidzin & $75 \% \pm 0$ & 20 & $97 \% \pm 2$ & 0.4 \\
\hline Puerarin & $114 \% \pm 1$ & 38 & $93 \% \pm 2$ & 0.3 \\
\hline Formononetin & $45 \% \pm 1$ & 76 & $92 \% \pm 2$ & 0.4 \\
\hline Genistein & $29 \% \pm 0$ & 21 & $111 \% \pm 2$ & 0.3 \\
\hline Genistin & $53 \% \pm 1$ & 31 & $114 \% \pm 1$ & 0.2 \\
\hline Biochanin A & $34 \% \pm 0$ & 34 & $76 \% \pm 1$ & 0.2 \\
\hline Sissotrin & $70 \% \pm 0$ & 11 & $146 \% \pm 2$ & 0.2 \\
\hline Medicarpin & $67 \% \pm 2$ & 241 & $119 \% \pm 9$ & 4 \\
\hline Coumestrol & $25 \% \pm 1$ & 52 & $69 \% \pm 3$ & 0.4 \\
\hline
\end{tabular}

ND: not detected.

${ }^{a}$ Adjusted for matrix interference: mean of six replicates.

both aglycones and glycoside derivatives is important when investigating the role of flavonoids inside white clover plants. The total content of flavonols was much higher than that of isoflavonoids and flavones in leaflets and flower heads of white clover plants, while isoflavonoids were more abundant in stalks, stems, and roots. The isoflavonoids and flavones probably have other biological functions than the flavonols, since it has been shown that the concentrations of the isoflavones formononetin and daidzein in roots of white clover increased in response to infection with the root pathogen Pythium ultimum [15].

Previous reports of total isoflavone concentrations in white clover plants ranged between 0.09 and $1.0 \mathrm{mg} / \mathrm{g}$ dry weight $[12,16-19]$, with isoflavonoids predominantly occurring as glycoside conjugates [20, 21], and formononetin glucoside-(di)-malonate(s) and medicarpin-glucosidemalonate being the major isoflavonoids in white clover plants $[19,21]$. In our study we did not quantify sugar conjugates of formononetin or medicarpin, but the concentrations of the aglycones of those two compounds were high compared to previous reports. The elevated concentrations were possibly a result of differences between cultivars, analytical methods, or growing conditions. Alternatively, the formononetin and medicarpin glycosides may have undergone hydrolysis before or during analysis.

Hyperoside concentrations represented a large portion of the total flavonoid content in white clover flower heads (Table 5) which was consistent with previous reports of hyperoside in flowers $[13,22]$. Hyperoside, quercetin- $\left(6^{\prime \prime}-O-\right.$ acetyl)-3-O-galactoside (quercetin acetyl-Gal), and myricetin-3-O-galactoside (myricetin-Gal) have been reported as the major flavonoids of white clover flowers [22], and hyperoside was also reported as one of the major flavonoids from flowers of an experimental population selected for high prodelphinidin content [23], suggesting a correlation between the two.

In keeping with our previous findings [13] the concentrations of quercetin and kaempferol aglycones found in 
TABLE 5: Concentrations in plant tissues and whole plants before incorporation ( $\mu \mathrm{mol} / \mathrm{kg}$ dry weight). Values represent the mean of two replicate analyses.

\begin{tabular}{|c|c|c|c|c|c|}
\hline Compound & Roots & Stalks and stems & Leaflets & Flower heads & Whole plants \\
\hline Kaempferol & ND & ND & 4.8 & 17 & 2.0 \\
\hline Astragalin & 0.3 & 0.4 & 4.1 & 0.6 & 1.0 \\
\hline Kaempferol-Rha-Xyl-Gal & 5.3 & 92 & 2681 & 1100 & 577 \\
\hline Quercetin & ND & ND & ND & 56 & 4.3 \\
\hline Hyperoside & 4.2 & 17 & 427 & 5167 & 473 \\
\hline Quercetin-Xyl-Gal & 6.2 & 286 & 5752 & 3838 & 1415 \\
\hline Rutin & 0.6 & ND & ND & 33 & 2.5 \\
\hline Quercetin-Rha-Xyl-Gal & 0.7 & 9.4 & 36 & 318 & 37 \\
\hline Apigenin & 0.2 & 0.1 & ND & ND & 0.1 \\
\hline Saponarin & 45 & 13 & 21 & 25 & 16 \\
\hline Luteolin & 3.1 & 5.4 & 6.7 & 11 & 5.9 \\
\hline Luteolin-Glc & 1.1 & 6.9 & 17 & 15 & 8.9 \\
\hline Luteolin-di-Glc & 1.5 & 2.1 & 5.4 & 0.5 & 2.5 \\
\hline Naringenin & ND & 0.1 & 0.1 & 0.3 & 0.1 \\
\hline Daidzein & 0.3 & 0.2 & 0.7 & 2.2 & 0.4 \\
\hline Daidzin & 0.9 & 1.5 & 10 & 2.4 & 2.9 \\
\hline Formononetin & 2791 & 4896 & 3265 & 4085 & 4497 \\
\hline Genistein & 0.3 & 0.5 & 1.0 & 6.2 & 1.0 \\
\hline Genistin & 3.7 & 3.1 & 9.6 & 14 & 5.0 \\
\hline Biochanin A & 0.9 & 1.5 & 0.7 & 4.2 & 1.5 \\
\hline Sissotrin & 1.4 & 0.5 & 1.4 & 0.9 & 0.7 \\
\hline Medicarpin & 600 & 939 & 878 & 1383 & 950 \\
\hline Coumestrol & 0.8 & 0.2 & 0.5 & 0.4 & 0.3 \\
\hline
\end{tabular}

white clover flower heads were much higher than those found in leaflets, stalks, stems, or roots (see Table 5). Flavonol aglycones have been isolated and identified as the active compounds required to produce functional pollen tubes in CHS200 deficient petunia, with the activity being highest for kaempferol and isorhamnetin, followed by quercetin and myricetin [24]. The high concentrations of quercetin and kaempferol aglycones in flower heads are therefore likely due to the participation of those compounds in pollen fertility.

Leaflets of the cultivar Klondike had a significantly higher concentration of quercetin-Xyl-Gal than other parts of the plant. Similarly, we previously reported the relative concentration of quercetin-Xyl-Gal and kaempferol-Xyl-Gal in leaflets and stalks rather than flower heads [13]. Other studies have shown that the most abundant flavonoids in white clover leaves were quercetin and kaempferol derivatives, with quercetin-Xyl-Gal and kaempferol-Xyl-Gal being the most important in UV-B-irradiated plants $[25,26]$. Notably, these flavonoids were also shown to protect against UV-B-induced stress, and their location in leaflets is consistent with a need for UV-B stress response there. The concentrations of quercetin and kaempferol glycosides (see Table 5) were comparable to those reported for UV-B-irradiated plants, while much lower concentrations were found in control plants [25], suggesting that differences among cultivars, growing conditions, and analytical methods may overshadow a putative UV response. Quantitative HPLC analysis using diode array detection of plant metabolites as performed in the cited studies is often subject to severe matrix interferences that may be unavoidable even after preprocessing by solid phase extraction [27].

4.2. Fate in Soil of Flavonoids Released from Living White Clover Plants. When roots actively release chemical compounds, they may regulate the resident microbial community in the soil, promoting beneficial symbioses that inhibit the growth of competing plant species [28, 29]. Even higher concentrations may have been found if soil samples had been collected nearer to the roots. Formononetin can stimulate growth of white clover shoots and colonization and nodule number of an arbuscular-mycorrhizal fungus [30], and both formononetin and medicarpin can inhibit radial growth of pathogenic fungi [31]. The release of these compounds can thus significantly affect the growth of white clover. Differences in the capacity and mechanism of release of these compounds by the variety of white clover cultivars require further study. It is likely, however, that the measured compounds were exuded from Trifolium roots without microbial modification as they are known to occur in planta [13]. 


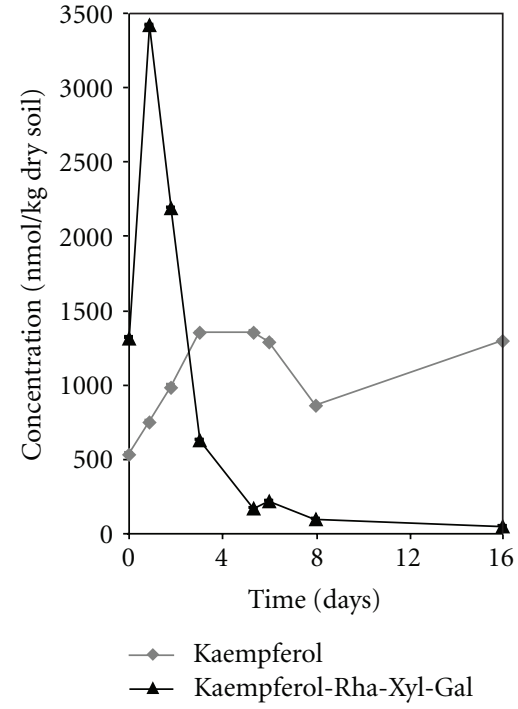

(a)

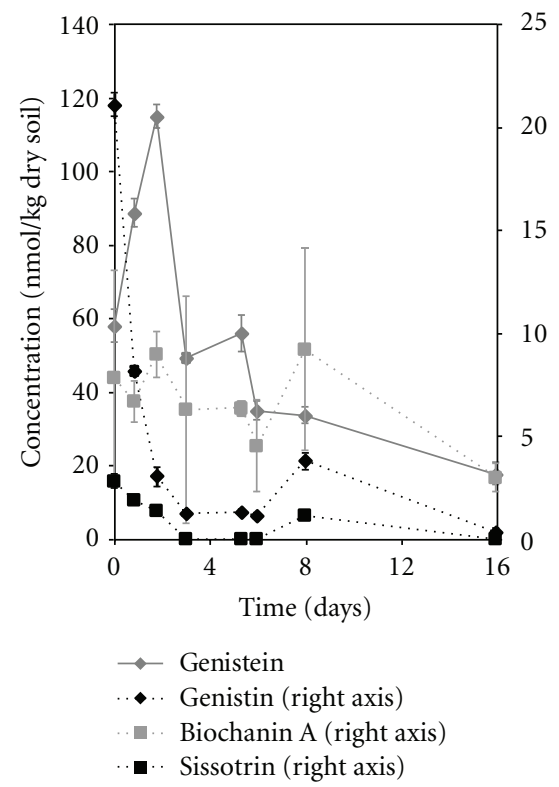

(d)

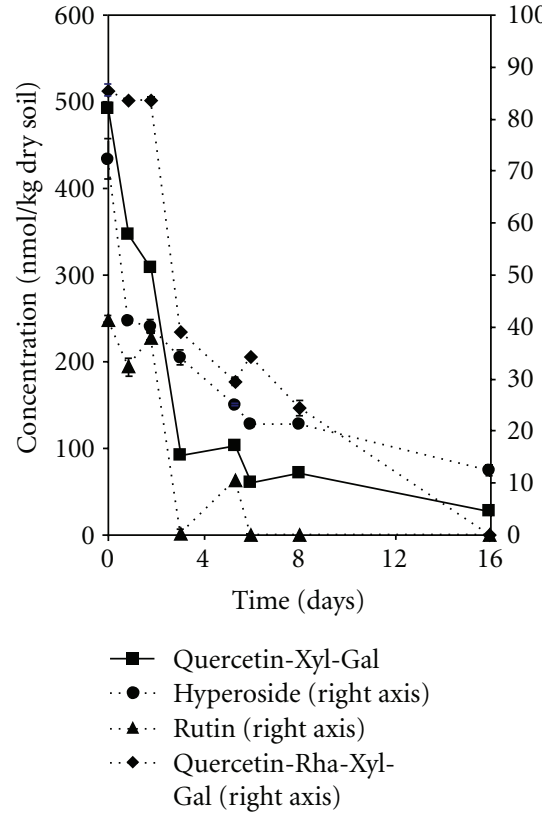

(b)

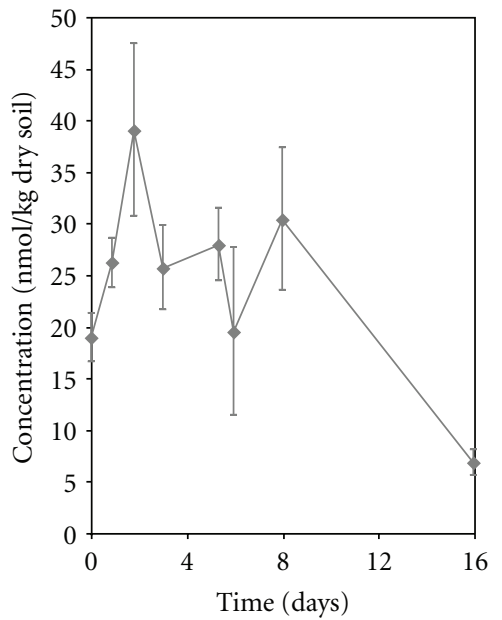

$\checkmark$ Coumestrol

(e)

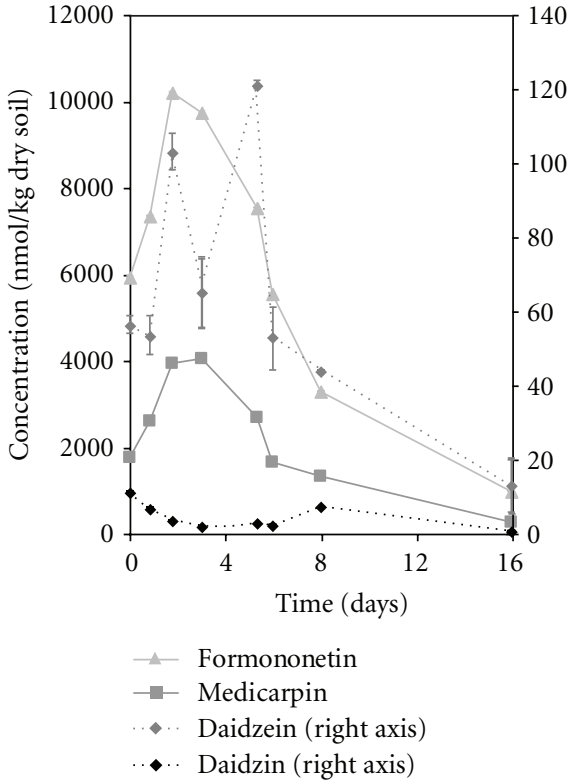

(c)

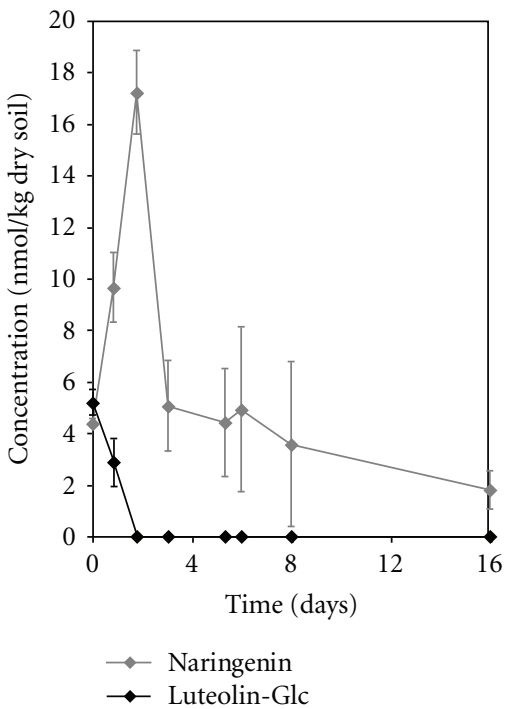

(f)

Figure 1: Time profiles of the concentrations of flavonoids leached into clover-amended soil. Error bars indicate 95\% confidence intervals.

4.3. Fate of Flavonoids in Soil Amended with White Clover. Flavonoids from the white clover cultivar Klondike were leached from plant material after incorporation into the soil. The degradation of most flavonoid glycosides in the soil occurred rapidly and coincided with increased abundances of the aglycones. We previously reported that the soil concentrations of most flavonoids for the cultivars Aran and Rabani were, respectively, 1.7 and 2.5 times that for Klondike [13]. Depending on cultivar and growth conditions, flavonoid concentrations in different soil environments can therefore be higher than those observed in this study.

The free aglycone kaempferol, detected in the soil after incorporation of white clover plants, probably leached into the soil in its free form and was most likely formed after degradation of kaempferol-Rha-Xyl-Gal and kaempferolXyl-Gal. The latter compound was not included in this study as a standard was unavailable. Carlsen et al. [13], however, previously showed that this compound was one of 
TABLE 6: The maximum available concentration in soil B after incorporation of white clover plant material and at $t=16$ days after incorporation, and the concentration of available flavonoids in soil A ( $\mathrm{nmol} / \mathrm{kg}$ dry weight). Values represent the mean of two replicate analyses.

\begin{tabular}{|c|c|c|c|}
\hline \multirow{2}{*}{ Compound } & \multicolumn{2}{|c|}{ Soil B (used for incorporation) } & \multirow{2}{*}{ Soil A (used for cultivation) } \\
\hline & $\begin{array}{c}\text { Max conc. } \\
\text { (at time (days)) }\end{array}$ & $\begin{array}{c}\text { Conc. at } \\
t=16 \text { days }\end{array}$ & \\
\hline Kaempferol & $1355(t=5)$ & 1297 & 520 \\
\hline Astragalin & ND & ND & ND \\
\hline Kaempferol-Rha-Xyl-Gal & $3417(t=1)$ & 50 & 51 \\
\hline Quercetin & ND & ND & ND \\
\hline Hyperoside & $72(t=0)$ & 12 & ND \\
\hline Quercetin-Xyl-Gal & $492(t=0)$ & 27 & 16 \\
\hline Rutin & $41(t=0)$ & ND & ND \\
\hline Quercetin-Rha-Xyl-Gal & $85(t=0)$ & ND & ND \\
\hline Apigenin & ND & ND & ND \\
\hline Saponarin & ND & ND & ND \\
\hline Luteolin & ND & ND & ND \\
\hline Luteolin-Glc & $5.2(t=0)$ & ND & ND \\
\hline Luteolin-di-Glc & $5.4(t=3)$ & 4.4 & ND \\
\hline Naringenin & $17(t=2)$ & 1.8 & 1.9 \\
\hline Daidzein & $121(t=5)$ & 13 & 24 \\
\hline Daidzin & $11(t=0)$ & 0.5 & 5.4 \\
\hline Formononetin & $10234(t=2)$ & 1009 & 9114 \\
\hline Genistein & $115(t=2)$ & 18 & 3.7 \\
\hline Genistin & $21(t=0)$ & 0.3 & 3.8 \\
\hline Biochanin A & $13(t=2)$ & 5.4 & 3.8 \\
\hline Sissotrin & $2.8(t=0)$ & ND & 2.3 \\
\hline Medicarpin & $3940(t=2)$ & 277 & 832 \\
\hline Coumestrol & $39(t=2)$ & 6.8 & 22 \\
\hline
\end{tabular}

the major white clover flavonoids. The highest concentration of kaempferol was found on day 5 (1355 nmol/kg dry weight) after which it decreased slightly before rising once again. The residence time of kaempferol in soil remains to be investigated but possible effects of kaempferol or its derivatives on subsequent crops should not be discounted, since kaempferol has been shown to inhibit mitochondrial phosphorylation in corn, protoplasmic streaming in oat root hairs [32-34], and ATP formation in mitochondria of cucumber hypotyls and roots, maize coleoptiles, and pea roots [32]. Whether kaempferol autotoxicity is a factor in clover soil fatigue should be investigated.

Upon incorporation of clover plants into the soil, the formononetin concentration nearly doubled to reach a maximum between days 3 and 5. This may have been due to the release and subsequent degradation of formononetin glycosides from the clover plants. Formononetin glycosides were not measured in this study, but several formononetin-glucoside-(di)-malonate(s) are known to be major isoflavonoids in white clover $[19,21]$. In several cases, formononetin has been shown to be degraded to daidzein in environments dominated by bacteria or fungi [12]. The time lag observed between the maximum concentrations of these compounds ( $t=2$ versus $t=5 \mathrm{~d}$, Table 6 ) may have arisen because the degradation of formononetin caused a second, larger, maximum in the daidzein concentration. The first maximum in the daidzein concentration, by contrast, probably stemmed from the degradation of glycoside daidzin. The concentration of medicarpin increased from day 0-3 and then decreased rapidly. The capacity of formononetin and medicarpin to exert their important positive effects on white clover growth and arbuscular-mycorrhizal colonization appears therefore only to exist during the early stages, or when released during growth.

The concentration of Quercetin-Xyl-Gal decreased rapidly from day 0 to day 3 . No quercetin was shown to arise in response to the degradation of the glycosylated form, but this was likely due to the low recovery of quercetin from soil (Table 4).

4.4. Environmental Risks from Flavonoids. The most abundant flavonoid aglycones detected in the soil were formononetin, medicarpin, and kaempferol. The total concentrations of these compounds in soils amended with white clover plants, were almost certainly higher than those actually determined in this study. The recovery experiment 
suggested significant soil sorption as reflected in the diminished extractable concentrations. Though detection of the quercetin aglycone was poor, high concentrations of the glycoside were found and this flavonoid should be included in future studies. The $K_{\mathrm{OC}}$ values for these four aglycones as estimated using PCKOCWIN were as follows: Kaempferol, 327; quercetin, 510; formononetin, 1600; and medicarpin, 33570. In comparison, an experimental $K_{\mathrm{OC}}$ value of 1318 has been reported for formononetin [35]. Leaching of kaempferol and quercetin to groundwater is therefore likely and should be included in overall risk assessments in the future, remembering that synthetic pesticides are not the only compounds that can have negative health effects on agricultural practices or humans.

\section{Acknowledgments}

The authors thank Dr. Paul M. Dewick of the University of Nottingham for providing a sample of medicarpin. This project was funded internally by Aarhus University.

\section{References}

[1] M. J. Macfarlane, D. Scott, and P. Jarvis, "Allelopathic effects of white clover .2. Field investigations in tussock grasslands," New Zealand Journal of Agricultural Research, vol. 25, no. 4, pp. 511-518, 1982.

[2] F. C. Stevenson and C. Van Kessel, "A landscape-scale assessment of the nitrogen and non-nitrogen rotation benefits of pea," Soil Science Society of America Journal, vol. 60, no. 6, pp. 1797-1805, 1996.

[3] T. G. Reeves, A. Ellington, and H. D. Brooke, "Effects of lupinwheat rotations on soil fertility, crop disease and crop yields," Australian Journal of Experimental Agriculture, vol. 24, no. 127, pp. 595-600, 1984.

[4] A. D. Doyle, K. J. Moore, and D. F. Herridge, "The narrowleafed lupin (Lupinus Angustifolius L.) as a nitrogen- fixing rotation crop for cereal production. III. Residual effects of lupins on subsequent cereal crops," Australian Journal of Agricultural Research, vol. 39, no. 6, pp. 1029-1037, 1989.

[5] G. W. Clayton, W. A. Rice, N. Z. Lupwayi, and T. K. Turkington, "Sustainability of legume-based conservation tillage systems," Final Technical Report on CAESA Project 9415, 1997.

[6] E. A. Grant and W. G. Sallans, "Influence of plant extracts on germination and growth of eight forage species," Journal of the British Grassland Society, vol. 19, pp. 191-197, 1964.

[7] E. I. Newman and A. D. Rovira, "Allelopathy among some british grassland species," Journal of Ecology, vol. 63, no. 3, pp. 727-737, 1975.

[8] D. Scott, "Allelopathic interactions of resident tussock grassland species on germination of oversown seed," New Zealand Journal of Experimental Agriculture, vol. 3, pp. 135-141, 1975.

[9] C. N. Hale, W. L. Lowther, and J. M. Lloyd, "Effect of inoculant formulation on survival of Rhizobium trifolii and the establishment of oversown white clover (Trifolium repens)," New Zealand Journal of Experimental Agriculture, vol. 7, no. 3, pp. 311-314, 1979.

[10] C. N. Hale and D. J. Mathers, "Toxicity of white clover seed diffusate and its effect on survival of Rhizobium trifolii," New Zealand Journal of Agricultural Research, vol. 20, no. 1, pp. 6973, 1977.
[11] T. L. Widmer and G. S. Abawi, Management of Nematodes by the Use of Cover Crops and Their Incorporation as Green Manures, Nematode Pests in Rice-Wheat Legume Cropping Systems: Proceedings of a Regional Training Course, CCS Haryana Agricultural University, Haryana, India; Rice-Wheat Consortium for the Indo-Gangetic Plains, New Delhi, India, 1998.

[12] S. C. K. Carlsen and I. S. Fomsgaard, "Biologically active secondary metabolites in white clover (Trifolium repens L.) - a review focusing on contents in the plant, plant-pest interactions and transformation," Chemoecology, vol. 18, no. 3, pp. 129-170, 2008.

[13] S. C. K. Carlsen, A. G. Mortensen, W. Oleszek, S. Piacente, A. Stochmal, and I. S. Fomsgaard, "Variation in flavonoids in leaves, stems and flowers of white clover cultivars," Natural Product Communications, vol. 3, no. 8, pp. 1299-1306, 2008.

[14] M. Thompson, S. L. R. Ellison, A. Fajgelj, P. Willetts, and R. Wood, "Harmonised guidelines for the use of recovery information in analytical measurement (technical report)," Pure and Applied Chemistry, vol. 71, no. 2, pp. 337-348, 1999.

[15] S. C. K. Carlsen, A. Understrup, I. S. Fomsgaard, A. G. Mortensen, and S. Ravnskov, "Flavonoids in roots of white clover: interaction of arbuscular mycorrhizal fungi and a pathogenic fungus," Plant and Soil, vol. 302, no. 1-2, pp. 3343, 2008 .

[16] M. Jurzysta, S. Burda, and J. Zurek, "Wystepowanie izoflawonów w krajowych gatunkach koniczyny," Acta Agrobotanica, vol. 41, pp. 77-90, 1988.

[17] H. Saloniemi, K. Kallela, and I. Saastamoinen, "Study of the phytoestrogen content of goat's rue (Galega orientalis), alfalfa (Medicago sativa) and white clover (Trifolium repens)," Agricultural Science in Finland, vol. 2, no. 6, pp. 517-524, 1993.

[18] Q. Wu, M. Wang, and J. E. Simon, "Determination of isoflavones in red clover and related species by high-performance liquid chromatography combined with ultraviolet and mass spectrometric detection," Journal of Chromatography A, vol. 1016, no. 2, pp. 195-209, 2003.

[19] E. De Rijke, H. Zappey, F. Ariese, C. Gooijer, and U. A. T. Brinkman, "Flavonoids in Leguminosae: analysis of extracts of T. pratense L., T. dubium L., T. repens L., and L. corniculatus L. leaves using liquid chromatography with UV, mass spectrometric and fluorescence detection," Analytical and Bioanalytical Chemistry, vol. 378, no. 4, pp. 995-1006, 2004.

[20] C. M. Francis, A. J. Millington, and E. T. Bailey, "Distribution of oestrogenic isoflavones in genus Trifolium," Australian Journal of Agricultural Research, vol. 18, no. 1, pp. 47-54, 1967.

[21] R. Cook, S. A. Tiller, K. A. Mizen, and R. Edwards, "Isoflavonoid metabolism in resistant and susceptible cultivars of white clover infected with the stem nematode Ditylenchus dipsaci," Journal of Plant Physiology, vol. 146, no. 3, pp. 348-354, 1995.

[22] U. Schittko, F. Burghardt, K. Fiedler, V. Wray, and P. Proksch, "Sequestration and distribution of flavonoids in the common blue butterfly Polyommatus icarus reared on Trifolium repens," Phytochemistry, vol. 51, no. 5, pp. 609-614, 1999.

[23] L. Y. Foo, Y. Lu, A. L. Molan, D. R. Woodfield, and W. C. McNabb, "The phenols and prodelphinidins of white clover flowers," Phytochemistry, vol. 54, no. 5, pp. 539-548, 2000.

[24] Y. Mo, C. Nagel, and L. P. Taylor, "Biochemical complementation of chalcone synthase mutants defines a role for flavonols in functional pollen," Proceedings of the National Academy of Sciences of the United States of America, vol. 89, no. 15, pp. 7213-7217, 1992.

[25] R. W. Hofmann, E. E. Swinny, S. J. Bloor et al., "Responses of nine Trifolium repens L. populations to ultraviolet-B radiation: differential flavonol glycoside accumulation and biomass 
production," Annals of Botany, vol. 86, no. 3, pp. 527-537, 2000.

[26] R. W. Hofmann, B. D. Campbell, S. J. Bloor et al., "Responses to UV-B radiation in Trifolium repens L.-physiological links to plant productivity and water availability," Plant, Cell and Environment, vol. 26, no. 4, pp. 603-612, 2003.

[27] E. Eljarrat, M. Guillamón, J. Seuma et al., "First European interlaboratory study of the analysis of benzoxazinone derivatives in plants by liquid chromatography," Journal of Chromatography A, vol. 1047, no. 1, pp. 69-76, 2004.

[28] S. Nardi, G. Concheri, D. Pizzeghello, A. Sturaro, R. Rella, and G. Parvoli, "Soil organic matter mobilization by root exudates," Chemosphere, vol. 41, no. 5, pp. 653-658, 2000.

[29] T. S. Walker, H. P. Bais, E. Grotewold, and J. M. Vivanco, "Root exudation and rhizosphere biology," Plant Physiology, vol. 132, no. 1 , pp. 44-51, 2003.

[30] J. O. Siqueira, G. R. Safir, and M. G. Nair, "Stimulation of vesicular-arbuscular mycorrhiza formation and growth of white clover by flavonoid compounds," New Phytologist, vol. 118, no. 1, pp. 87-93, 1991.

[31] H. D. VanEtten, "Antifungal activity of pterocarpans and other selected isoflavonoids," Phytochemistry, vol. 15, no. 5, pp. 655659, 1976.

[32] G. Stenlid, "Flavonoids as inhibitors of the formation of adenosine triphosphate in plant mitochondria," Phytochemistry, vol. 9, no. 11, pp. 2251-2256, 1970.

[33] D. E. Koeppe and R. J. Miller, "Kaempferol inhibitions of corn mitochondrial phosphorylation," Plant Physiology, vol. 54, no. 3, pp. 374-378, 1974.

[34] G. Popovici and H. Reznik, "Effect of some flavonoids on protoplasmic streaming in oat (Avena sativa) root hairs," Zeitschrift fur Pflanzenphysiologie, vol. 80, no. 5, pp. 417-425, 1976.

[35] L. J. Shaw and J. E. Hooker, "The fate and toxicity of the flavonoids naringenin and formononetin in soil," Soil Biology and Biochemistry, vol. 40, no. 2, pp. 528-536, 2008. 

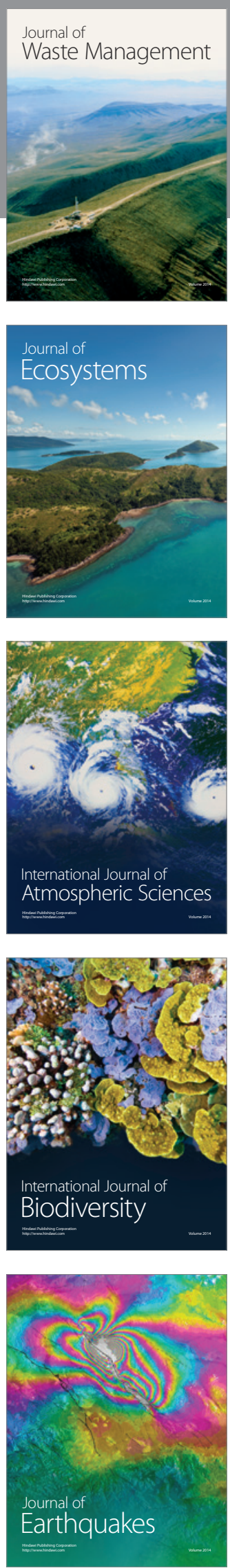
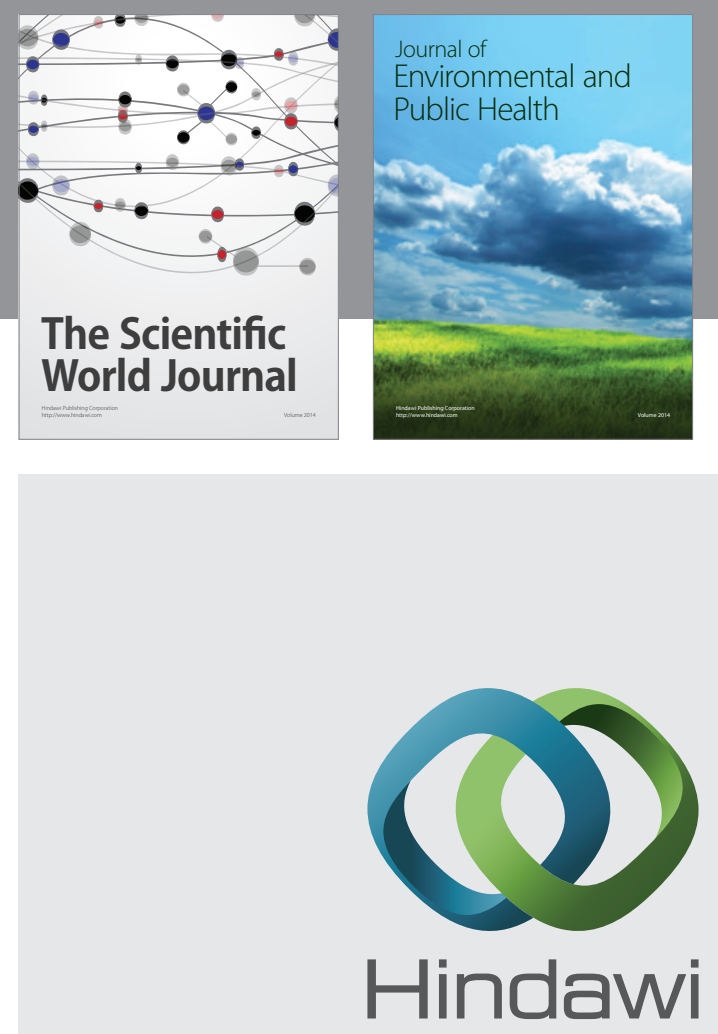

Submit your manuscripts at

http://www.hindawi.com
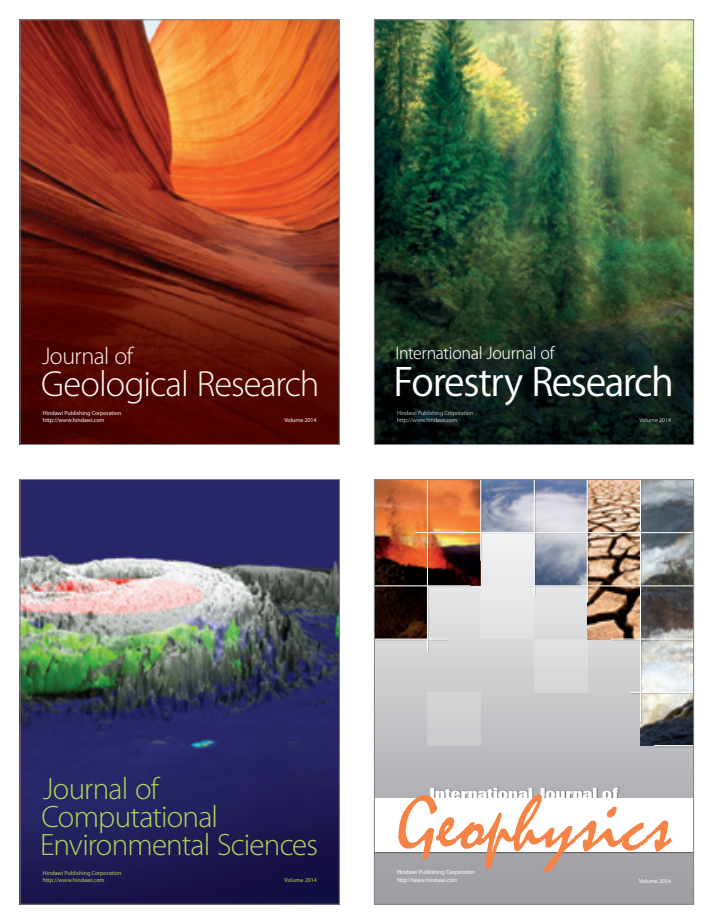
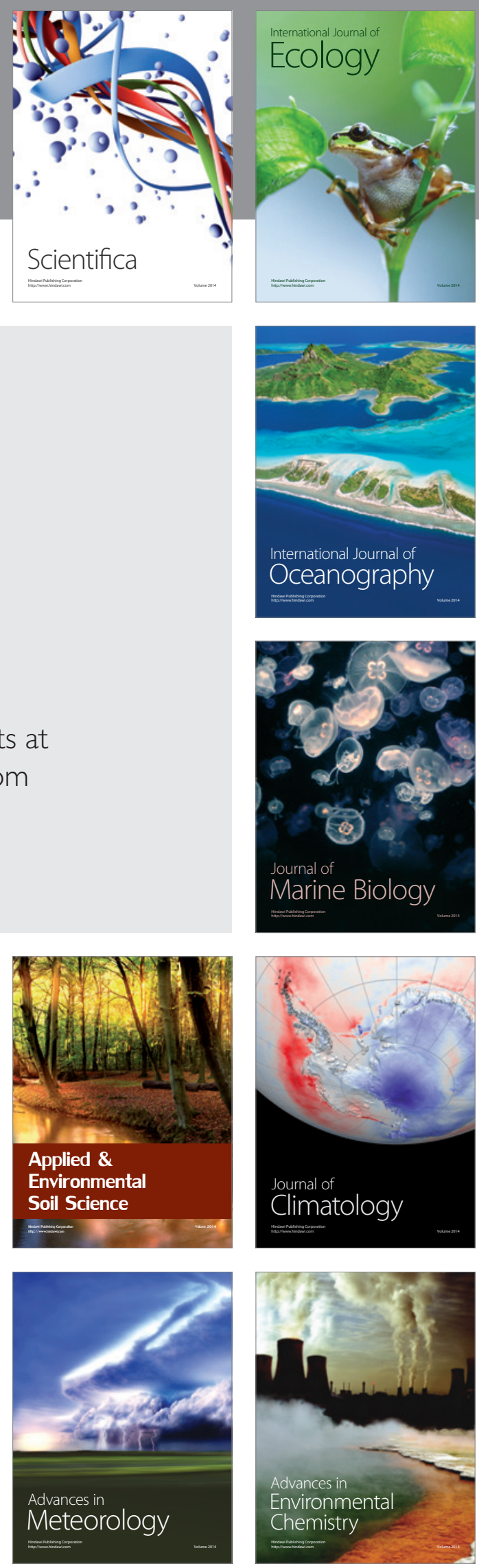